\title{
Hybrids membranes with potential for fuel cells - Part 3: extruded films of nanocomposites based on sepiolite and PC/sulfonated PC blends
}

\author{
Ana Catarina de Oliveira Gomes ${ }^{1 *}$, Eduardo Henrique Backes ${ }^{1}$, Adhemar Colla Ruvolo Filho ${ }^{1}$, \\ Caio Marcio Paranhos ${ }^{2}$, Fábio Roberto Passador ${ }^{3}$ and Luiz Antonio Pessan ${ }^{1}$
}

\author{
'Laboratório de Permeação e Sorção - LAPS, Departamento de Engenharia de Materiais, Universidade \\ Federal de São Carlos - UFSCar, São Carlos, SP, Brasil \\ 'Laboratório de Polímeros - LabPol, Departamento de Química, Universidade Federal de São Carlos - \\ UFSCar, São Carlos, SP, Brasil \\ ${ }^{3}$ Instituto de Ciência e Tecnologia, Universidade Federal de São Paulo - UNIFESP, São José dos Campos, \\ SP, Brasil \\ *acogomes@gmail.com
}

\begin{abstract}
Fuel Cells based in polymers are an alternative for the conventional energetic matrices. However, materials currently available still present disadvantages to overcome. Membranes of polycarbonate (PC)/sulfonated polycarbonate (PCs) blend/sepiolite nanocomposites have previously been studied by the authors, resulting in good mechanical properties and promising properties of vapor transmission and ionic migration resistance. However, their production in large scale is still a challenge. The aim of this work was the development further the formulation and processing of the previously studied material. Films of PC/PCs blends (50/50 wt \%) with different content of sepiolite clay, with and without chemical modification, have been prepared in an extruder and evaluated by FTIR, XRD, DSC, TGA, DMA, tension strength and water vapor transmission (WVT). Even after two processing steps, the blend-based nanocomposites keep good thermal and mechanical properties. However, changes in WVT were observed with respect to data obtained in previous studies.
\end{abstract}

Keywords: polymeric membrane, nanocomposite, fuel cell, polymeric electrolyte.

\section{Introduction}

Fuel cells are considered the future of clean sustainable energy, besides being considered the step to be overcome for the development and application of all new Technologies. The search field is powered by chronic and imminent problem of depletion of energy matrix based on fossil fuels, in addition to environmental factors that are well known and discussed in the media. Among several advantages of fuel cells compared to conventional power technologies, stand out the reduction of pollutant emissions, the higher efficiency and its simplicity ${ }^{[1,2]}$. In brief, fuel cells work oxidizing fuel at the anode, releasing electrons that are transported through an electrolyte to the cathode, where they react generating a byproduct and releasing heat. This electrolyte can be a polymeric membrane, which has as advantages the possibility of lower temperature applications, leading to a faster start of the system, smaller thickness for mounting and less weight of device, implicating in smaller and portable fuel cells, among other improvements. As disadvantages, there are the mechanical, thermal and electrochemical degradation of the polymeric membranes ${ }^{[1-3]}$.

Nanocomposites of sulfonated polymers has been studied for applications on fuel cells ${ }^{[4,5]}$. The use of polycarbonate (PC) chemically modified with sulfone groups and incorporation of sepiolite, though, is not found in literature, to our knowledge.

The bisphenol-A PC is an engineering thermoplastic, amorphous, tough, with impact resistance very superior to others thermoplastics at low temperatures ${ }^{[6]}$. Meanwhile the sepiolite is a natural hydrated magnesium silicate with a significant number of silanol groups $(\mathrm{Si}-\mathrm{OH})$ present on the surface of the mineral ${ }^{[7]}$. More information about system components can be found in our previous publications ${ }^{[8,9]}$.

In previous works of our group ${ }^{[8,9]}$, the sulfonation of the PC was successfully obtained, despite of generating small difference between the various contents of sulfonation agent tested. In fact, the sulfonation reaction of substituted aromatic rings have several issues regarding the extension of reaction, reversibility, and main chain scission as reported ${ }^{[4,10,11]}$. The mixture of chemically modified and not modified polymeric matrix generated a phase separation which can be beneficial to the desired application. The unmodified PC matrix is able to form a chemically and mechanical resistant structure while dispersed domains of the modified polymer can generate a percolated network to conduct protons in a more efficient and quick way. Even at low levels, the sulfonation was sufficient to promote phase separation and change the interaction between the matrix and the nanoparticles of 
sepiolite. The chemical modification decreased thermal resistance, as expected. This effect, however, was offset by the incorporation of nanoclay, although not fully solve the problem. In the case of sepiolite, the presence of the nanoparticle assisted in conducting ionic species across the membrane, unlike the observed in the literature for other clay minerals.

Sanchez et al. ${ }^{[12]}$ pointed to the importance of producing conductive polymer membrane using more applied processing methods, which, in addition to using an existing structure, can be considered an ecologically friendly process by not using large amounts of solvent, such as casting or phase inversion processes. The processing in the molten state, however, has its own challenges. The thermal stability of the polymer matrix, the chemically modified matrix and clay minerals, the influence of the presence of degradation products of these chemical modifiers, the shear strength, the development and stability of the morphology of the polymer blend during processing steps, among others.

Previous results ${ }^{[8,9]}$ showed great potential of these nanocomposites for use as solid electrolyte and the present study aimed to test its preparation in real processing conditions in which the incorporation of the clay mineral was carried out by mixing in the molten state, using a twin screw extruder and the molding was carried out by film extrusion. The goal was to achieve an appropriate balance among processing-structure-property for an optimized performance of the resulting membranes and to verify the possibility of industrial scale production, adapting the method of production of the membranes to the currently available technological park.

\section{Materials and Methods}

\subsection{Materials}

Polycarbonate (Lexan 103) used was donated by Sabic Corporation (density $1.20 \mathrm{~g} / \mathrm{cm}^{3}$; flow index $7.0 \mathrm{~g} / 10 \mathrm{~min}$ ). Dimethyldichlorosilane (DMDCS) was purchased from Sigma-Aldrich Inc, sepiolite clay from Flucka Inc and $\mathrm{N}$-methyl-pyrrolidone (NMP), sulfuric acid $\left(\mathrm{H}_{2} \mathrm{SO}_{4}\right)$, acetic anhydride (AcAn), ethyl alcohol (EtOH), toluene and dichloromethane (DCM) from Vetec Química S.A. All reagents have analytical grade and were used as received.

\subsection{Methods}

\subsubsection{Sulfonation of PC (PCs)}

The chemical modification was performed using "acetyl sulfate" as sulfonation agent with $75 \%\left(\mathrm{H}_{2} \mathrm{SO}_{4} / \mathrm{AcAn}\right.$ in volume) of concentration. The polymer was dissolved in $\mathrm{NMP}$ and the reaction was carried at $80^{\circ} \mathrm{C}$, in nitrogen atmosphere, drip addition of sulfonation agent through $1 \mathrm{~h}$, and another hour for reaction. The product was precipitated in $\mathrm{EtOH}$ and vacuum drying for $48 \mathrm{~h}^{[8-10]}$.

\subsubsection{Sepiolite modification}

The modification was carried out DMDCS 30\% (volume) in toluene, refluxed in soxhlet apparel for $6 \mathrm{~h}$ over neat sepiolite. The modified clay was washed and filtered with chloroform and methanol, and dried at vacuum at $120^{\circ} \mathrm{C}$ through $24 \mathrm{~h}^{[8,9,13]}$.

\subsubsection{Blend and nanocomposites preparation}

The PC/PCs blend (50/50\% in weight) and nanocomposites were prepared at molten state blend in a co-rotational twin-screw extruder MT19TC from B\&P Process Equipment and Systems with diameter of $19 \mathrm{~mm}$ e $\mathrm{L} / \mathrm{D}=25$, screw speed of $120 \mathrm{rpm}$, flow rate of $1 \mathrm{~kg} / \mathrm{h}$ and temperature profile of $200^{\circ} \mathrm{C} / 215^{\circ} \mathrm{C} / 225^{\circ} \mathrm{C} / 230^{\circ} \mathrm{C} / 240{ }^{\circ} \mathrm{C}$ from barrel to matrix. The produced samples are described in Table 1. The sample "PC w/ Proc" is a blank reference were PC was extruded into films directly from pellets, without previous processing, and the sample "Proc. PC" is another blank reference where neat PC was extruded in the twin screw extruder and them conformed into films.

\subsubsection{Films extrusion}

Films were produced in a flat film single screw extruder from AX Plastics, LAB16 model, with three heating zones $\left(215 / 225 / 235^{\circ} \mathrm{C}\right)$ from barrel to matrix. The drawing speed was $1 \mathrm{rpm}$.

\subsection{Characterizations}

The elemental analysis was used to evaluate the sulfonation degree (DS) in PCs samples and the test was performed in Eager 200 equipment from CE Intruments. The DS content, e.g. sulfur content in polymer matrix, it is obtained from Equation 1, where MMpol is the molecular weight of Polycarbonate monomeric unit, $\mathrm{S}$ is the sulfur content (weight percent), 32 and 80 are the molecular weight of Sulfur and sulfonic group, respectively ${ }^{[8,9,14]}$.

$$
D S=\frac{M M \operatorname{pol} X 100 X S}{32 X(100-80 S)}
$$

Infrared spectroscopy analyses were performed on film samples, with a FTIR Nicolet 6700 from Thermo Scientific, from 4500 to $400 \mathrm{~cm}^{-1}$ in absorbance mode.

The X-ray diffraction measurements were performed using a Rigaku Rotaflex Ru 200B diffractometer, using $\mathrm{Cu} \mathrm{K}(\alpha)$ radiation $(\lambda=1.5406 \AA)$, at a rate of $1 \% \mathrm{~min}$, operating at $40 \mathrm{kV}$ and $80 \mathrm{~mA}$, over $2 \theta$ range of $2^{\circ}-40^{\circ}$. The curves were submitted to a smoothing process using Savitzky-Golay method with a data window of 300 points.

The tensile tests were performed with an Instron universal testing machine, 5569 model, as ASTM D882-10 (5 mm

Table 1. Samples formulation (contents in phr).

\begin{tabular}{ccccc}
\hline Sample & PC & PCs & Sepiolite & Modified sepiolite \\
\hline PC w/ Proc. & 100 & - & - & - \\
Proc. PC & 100 & - & - & - \\
PCs & - & 100 & - & - \\
PC/PCs & 50 & 50 & - & - \\
Nano1 & 50 & 50 & 1.5 & - \\
Nano2 & 50 & 50 & 3.0 & - \\
Nano3 & 50 & 50 & - & 1.5 \\
Nano4 & 50 & 50 & - & 3.0 \\
\hline
\end{tabular}


/ min until $4 \%$ strain, following $50 \mathrm{~mm} / \mathrm{min}$ ). The testing samples were cut from films (thickness from $50-250 \mu \mathrm{m}$ ) by Franktseet cutter, in dimensions of 24 x $200 \mathrm{~mm}$ (width $\mathrm{x}$ length).

The differential scanning calorimetry (DSC) was measured using a Q2000 TA Instruments equipment, nitrogen atmosphere with flux of $50 \mathrm{ml} / \mathrm{min}$, temperature interval of 30 to $250^{\circ} \mathrm{C}$ and heat rate of $10{ }^{\circ} \mathrm{C} / \mathrm{min}$, with two heating cycles.

The thermogravimetric analysis (TGA) were performed using Q50 TA Instruments equipment, under nitrogen atmosphere, up to $800^{\circ} \mathrm{C}$ and heating rate of $20^{\circ} \mathrm{C} / \mathrm{min}$.

The dynamic-mechanical analysis (DMA) were performed in a Q800 TA Instruments equipment, in tension film accessory, temperature ramp of $3{ }^{\circ} \mathrm{C} / \mathrm{min}$ and deformation of $25 \mu \mathrm{m}$ at a frequency of $1 \mathrm{~Hz}$.

The water vapor uptake analyses were realized according to ASTM E96, with conditioning at $23{ }^{\circ} \mathrm{C}$ and humidity of $16 \%$, during five days.

\section{Results and Discussion}

The Elemental Analysis of sulfonated polycarbonate returns an average content of sulfur of $1.54 \mathrm{wt} \%$, corresponding to a sulfonation degree of approximately $12.7 \%$ for PCs.

Figure 1 shows infrared spectra of neat PC and PCs. The characteristics absorptions bands of the sulfone group $(\mathrm{S}=\mathrm{O})$ occur at 1684,1149 and $779 \mathrm{~cm}^{-1[8,9,11]}$. The band at $1690 \mathrm{~cm}^{-1}$ is observed in the PCs spectra indicating its sulfonation. The other bands are overlapped and cannot be differentiated.

There is no difference between proc. $\mathrm{PC}$ and $\mathrm{PC} \mathrm{w} /$ proc. (not shown), indicating no significant changes in chemical properties due the additional processing step.

Figures $2 \mathrm{a}$ and $\mathrm{b}$ shows FTIR spectra for the nanocomposites and PC/PCs blend prepared. It can be observed the characteristic peak of the sulfone group, as previously described. These results prove that even after two processing steps (twin screw extrusion and flat film extrusion) the structural modification with the sulfone group insertion was maintained. It is also noted that the nanocomposite with higher clay content shows lower peak intensity (in an approximated and naked eye comparing) than other samples. This difference can be attributed to a higher interaction of the non-modified clay with the sulfone groups of the modified matrix. This same effect was observed in previous works ${ }^{[8,9]}$.

For the nanocomposites with modified clay it is possible to observe a less significant effect in the band related to sulfone group, but there is a split in a band near to it $\left(1666 \mathrm{~cm}^{-1}\right)$ related to the main chain of polycarbonate. This split is probably related with a stronger interaction of the modified clay which is less polar, with the non-modified polycarbonate chain portion.

Figure 3a shows that samples without clay present a characteristic profile of amorphous materials as polycarbonate. The sulfonation, blending without clay (not shown) and processing in molten state do not alter this pattern in X-ray diffraction.

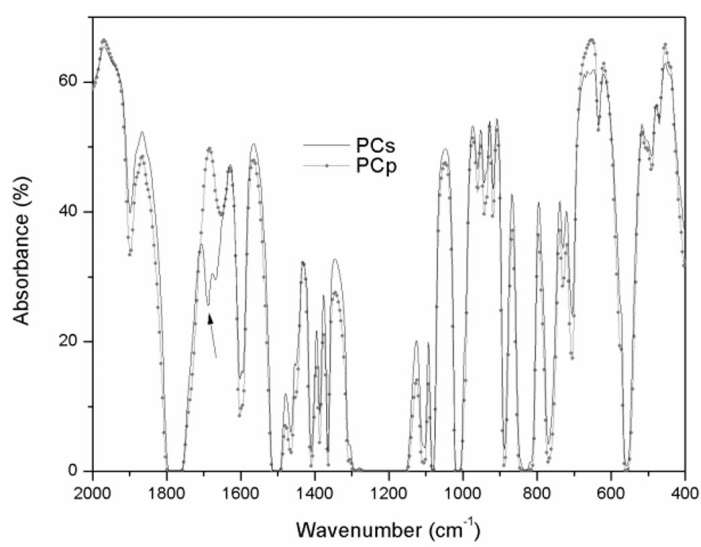

Figure 1. Infrared spectra of processed PC and PCs.

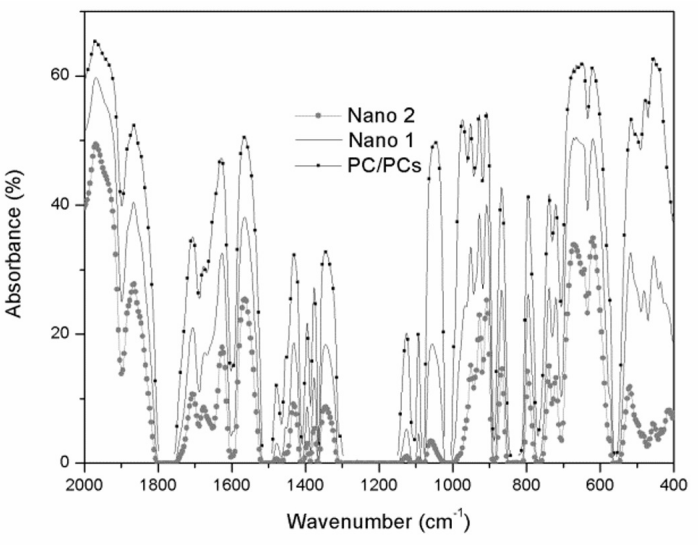

(a)

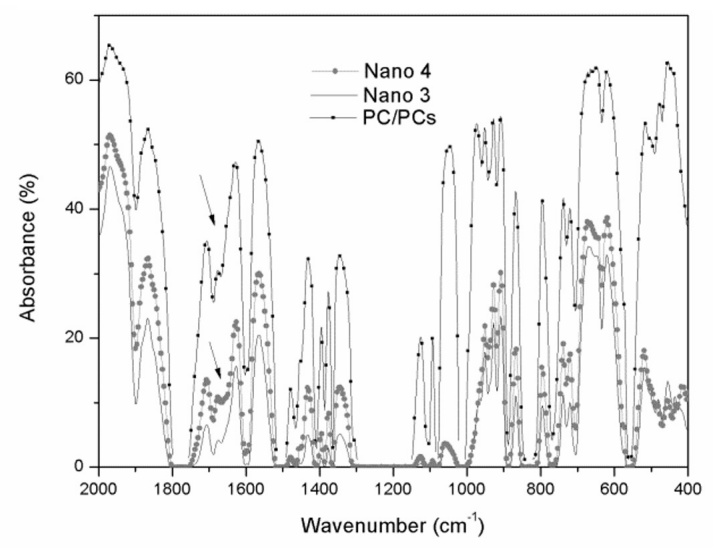

(b)

Figure 2. Infrared spectra of (a) PC/PCs, Nano1 and Nano2; (b) PC/PCs, Nano3 and Nano4. 
Diffratograms in Figure $3 \mathrm{~b}$ also show that nanocomposites differ from the neat matrix samples by a peak in the region of $7^{\circ}$, which is related to the sepiolite incorporation. This reflection is associated to spacing between crystalline planes that form the zeolitic pores of sepiolite ${ }^{[8]}$. The amorphous band referent to polymeric matrix does not alter.

\subsection{Tensile test}

Table 2 presents the stress $(\delta)$ versus strain $(\varepsilon)$ properties for the samples tested. The yield stress $\left(\delta_{\text {esc }}\right)$ and rupture stress $\left(\delta_{\text {rup }}\right)$ are not significantly affected by sulfonation and sepiolite insertion.

The elastic modulus (E) was determined from the linear portion of the stress versus strain curve, where the Hooke Law is valid. It can be noticed an increase in elastic modulus when comparing PC w/ Proc. to Proc. PC and PC/PCs blend.

This result can be correlated to the insertion of polar groups of PCs in the system that increases intersegmental interactions and results in a small increase of elastic modulus in PC/PCs blend. However this increase in stiffness led to a reduction in the elongation at break of approximately $6 \%$. According Smitha et al. ${ }^{[15]}$, the decreasing in elongation at break can also be associated to the increasing in free volume due sulfonation chemical modification.

Comparing the nanocomposites to $\mathrm{PC} / \mathrm{PCs}$ blend, it can be noticed an increase in the values of elastic modulus, except for Nano3. The superior elastic modulus of Nano 1, Nano 2 and Nano 4 indicates that the sepiolite is acting as a reinforcement increasing the rigidity of the material. The smaller amount $(1.5 \mathrm{wt} \%$ ) of modified sepiolite in Nano3 is possibly located in the non-modified component of the system, due to the higher hydrophilicity in this region reducing the rigidity of the sample. When the modified clay content increases (Nano 4), the elastic modulus becomes higher than the neat blend. These suppositions are supported by DMA results, presented ahead ${ }^{[8,9]}$. It is observed an increasing in modulus in the order of $9.7 \%$ for Nano $1,11.5 \%$ for Nano 2 and $7.8 \%$ for Nano 4 .

\subsection{Diferencial Scanning Calorimetry (DSC)}

The glass transition temperatures $\left(\mathrm{T}_{\mathrm{g}}\right)$ for the samples prepared were determined by DSC and the values obtained are presented in Table 3.

The neat PC show a $\mathrm{T}_{\mathrm{g}}$ value of $149.7^{\circ} \mathrm{C}$ at the first heating cycle, and $149.2^{\circ} \mathrm{C}$ at the second one. These values are close of the $150^{\circ} \mathrm{C}$ reported by literature ${ }^{[16]}$ and supplier. There is no variation of $\mathrm{T}_{\mathrm{g}}$ for the $\mathrm{PC}$ with (PC Proc) and without $(\mathrm{PC} \mathrm{w} /$ proc) processing. It can be noticed a reduction of $\mathrm{T}_{\mathrm{g}}$ in $\mathrm{PC} / \mathrm{PCs}$ blend due sulfonation, which can be related to the higher free volume among polymer chains due to the high volume of the functional group of the sulfone group. The nanocomposites blends have no significant variation in $\mathrm{T}_{\mathrm{g}}$ with the incorporation of increasing amount of clay

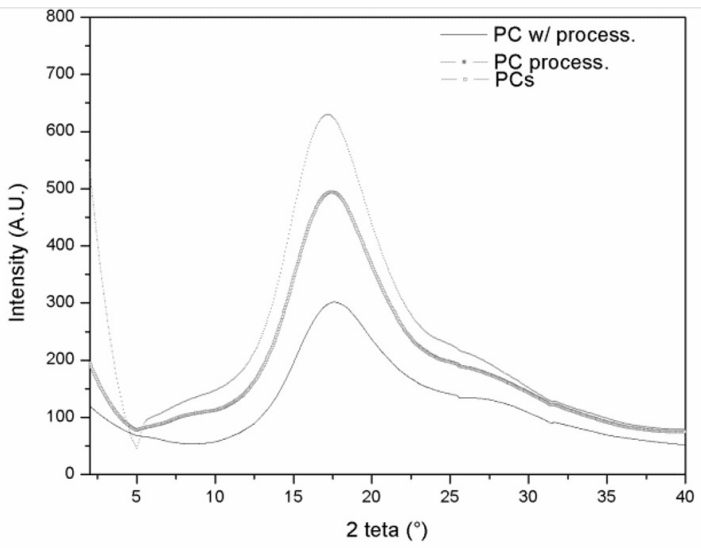

(a)

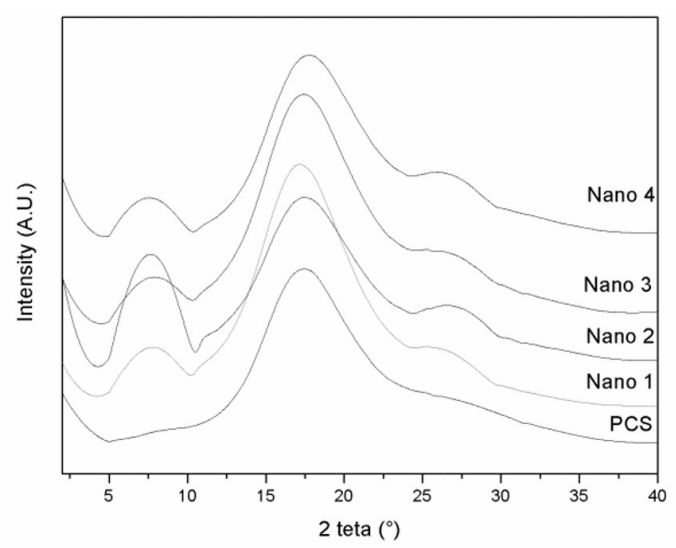

(b)

Figure 3. X-ray Difratograms of (a) neat polymers and PC/PCs blends; (b) nanocomposites.

Table 2. Mechanical properties in tensile strength

\begin{tabular}{ccccc}
\hline Sample & $\boldsymbol{\delta}_{\text {esc }}(\mathbf{M P a})$ & $\mathbf{E}(\mathbf{G P a})$ & $\boldsymbol{\delta}_{\text {rup }}(\mathbf{M P a})$ & $\boldsymbol{\varepsilon}_{\text {rup }}(\mathbf{\%})$ \\
\hline PC w/ Proc. & $53.9 \pm 4.4$ & $2.01 \pm 0.06$ & $55.8 \pm 4.5$ & $80.4 \pm 19.2$ \\
Proc. PC & $52.1 \pm 4.4$ & $2.10 \pm 0.05$ & $53.9 \pm 4.9$ & $91.6 \pm 15.9$ \\
PC/PCs & $54.3 \pm 4.0$ & $2.17 \pm 0.06$ & $54.0 \pm 3.7$ & $5.7 \pm 0.6$ \\
Nano1 & $55.4 \pm 3.5$ & $2.38 \pm 0.07$ & $55.1 \pm 3.4$ & $10.2 \pm 3.5$ \\
Nano2 & $51.8 \pm 2.3$ & $2.42 \pm 0.06$ & $51.3 \pm 2.8$ & $10.5 \pm 4.4$ \\
Nano3 & $53.5 \pm 2.7$ & $2.03 \pm 0.09$ & $54.7 \pm 3.4$ & $5.7 \pm 1.9$ \\
Nano4 & $55.1 \pm 1.8$ & $2.34 \pm 0.04$ & $54.7 \pm 2.0$ & $6.4 \pm 0.6$ \\
\hline
\end{tabular}


without or with modification. However, the variation of Tg is significant when comparing nanocomposites and PC/PCs blend. The more significant difference occurs for Nano2, with $3.0 \%$ of non-modified sepiolite, showing an increase of approximately $6{ }^{\circ} \mathrm{C}$ when compared to PC/PCs blend. There is no significant variation of $\mathrm{T}_{\mathrm{g}}$ observed in the first and second heating cycles, indicating that there was no stress relaxation from processing in the first heating cycle (as seen for the samples PC w/ Proc and Proc. PC).

\subsection{Thermogravimetric Analysis (TGA)}

Figure 4a presents TGA curves for neat and modified clays. The neat clay shows a significant reduction of mass (approximately $8 \%$ ) at $75^{\circ} \mathrm{C}$, follow by another mass loss $(2 \%)$ at $250^{\circ} \mathrm{C}$. From $450{ }^{\circ} \mathrm{C}$ there is a constant reduction of mass until $600^{\circ} \mathrm{C}$, where mass variation stabilizes, resulting in a residue of $85.3 \%$ at $800^{\circ} \mathrm{C}$. These transitions agree with the loss of water described for sepiolite where four types of interactions between the mineral structure and the water molecules results in four different transitions: hygroscopic

Table 3. $\mathrm{T}_{\mathrm{g}}$ set by DSC.

\begin{tabular}{ccc}
\hline Sample & $\mathbf{T}_{\mathbf{g}}\left({ }^{\circ} \mathbf{C}\right) \mathbf{1}^{\text {st heating }}$ & $\mathbf{T}_{\mathbf{g}}\left({ }^{\circ} \mathbf{C}\right) \mathbf{2}^{\text {nd heating. }}$ \\
\hline PC w/Proc. & 149.7 & 149.2 \\
Pc Proc. & 149.9 & 148.4 \\
PC/PCs & 132.7 & 132.0 \\
Nano1 & 136.0 & 135.8 \\
Nano2 & 138.3 & 138.1 \\
Nano3 & 133.0 & 133.5 \\
Nano4 & 135.2 & 135.5 \\
\hline
\end{tabular}

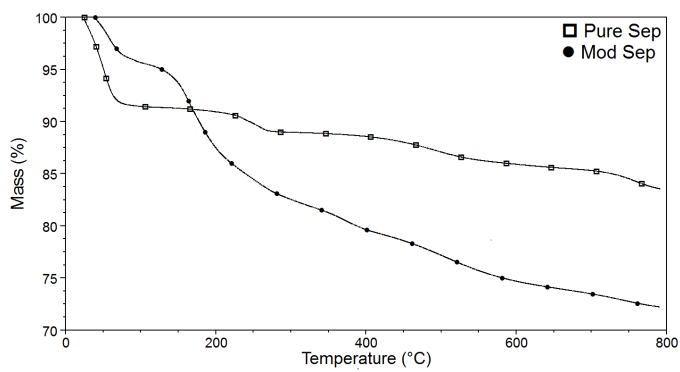

(a) adsorption (first transition), zeolitic adsorption (second transition), chemically adsorbed water (or linked - third transition) and structural water (a transition that would appear after $800^{\circ} \mathrm{C}$, a temperature higher than reached in our test $)^{[17,18]}$. The TGA curve of the modified clay shows an initial humidity loss of $4 \%$ at $65^{\circ} \mathrm{C}$, what can indicate a decrease in polarity due chemical modification. The observed behavior was similar to non-modified clay, except for an $8.5 \%$ loss at $540{ }^{\circ} \mathrm{C}$, which can be related to the degradation of the functional groups added during chemical modification of the clay surface. This difference was also observed by Tuhan et al. ${ }^{[18]}$. Finally, a residue of $85.3 \%$ is obtained at $800{ }^{\circ} \mathrm{C}$ of the modified clay analysis.

The PC/PCs blends showed similar behavior as compared to the nanocomposites (Figure 5b), only differing in the residue (Table 4) and maximum temperature of loss. There is a gradual loss of mass from $200{ }^{\circ} \mathrm{C}$ (humidity), followed by a significant mass loss in its main degradation step, around $500{ }^{\circ} \mathrm{C}$ (sulfone groups and main chain). The obtained dada for all samples are presented at Tables 4 , for flakes and films forms.

From the data in Table 4, it is noticed that the insertion of sulfone groups in PC chains increased slightly the degradation temperature for samples in film form. Similar behavior is found in literature ${ }^{[19]}$, but this difference can be insignificant, once at this point a first degradation step (of the sulfone groups) already occurred in the molecule ${ }^{[9]}$. The clay addition reduced the maximum degradation temperature for both cases, indicating an acceleration of degradation process. In the case of processed samples (film samples),

Figure 4. TGA curves of (a) pure and modified clay; (b) PC/PCs and nanocomposites samples.

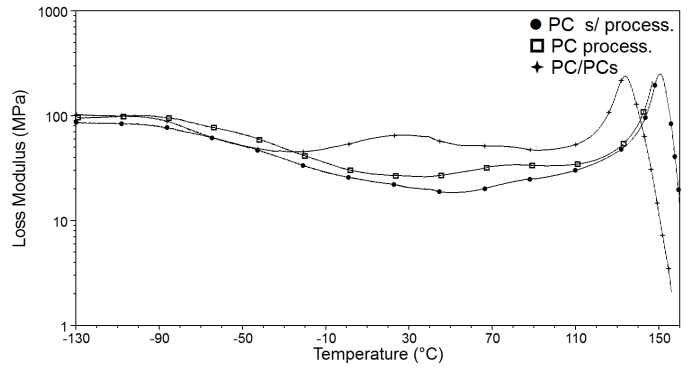

(a)

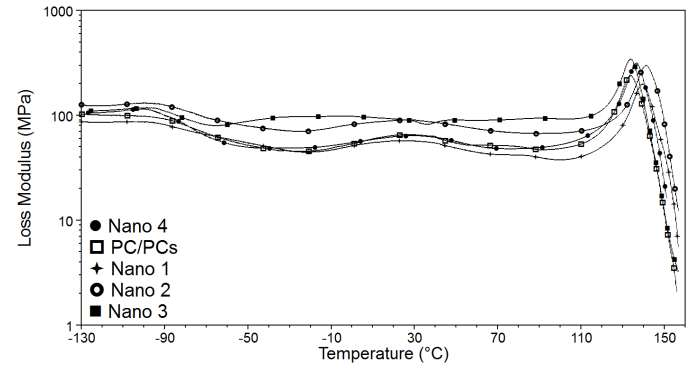

(b)

Figure 5. Loss modulus curves versus temperature for (a) PC Proc., PC s/ Proc. and PC/PCs blend; (b) PC/PCs blend and nanocomposites. 
Table 4. TGA data.

\begin{tabular}{|c|c|c|c|c|c|c|}
\hline \multirow[b]{2}{*}{ Sample } & \multicolumn{3}{|c|}{ FLAKES } & \multicolumn{3}{|c|}{ FILMS } \\
\hline & $\begin{array}{c}\text { Mass Loss } \\
(\%)\end{array}$ & $\begin{array}{l}\text { Max. Loss Temp. } \\
\left({ }^{\circ} \mathrm{C}\right)\end{array}$ & $\begin{array}{c}\text { Residue } \\
(\%)\end{array}$ & $\begin{array}{c}\text { Mass Loss } \\
(\%)\end{array}$ & $\begin{array}{l}\text { Max. Loss Temp. } \\
\left({ }^{\circ} \mathrm{C}\right)\end{array}$ & $\begin{array}{c}\text { Residue } \\
(\%)\end{array}$ \\
\hline Pc w/Proc & - & - & - & 78.3 & 523.5 & 22.1 \\
\hline PC Proc. & - & - & - & 78.5 & 529.9 & 21.7 \\
\hline $\mathrm{PC} / \mathrm{PCs}$ & 79.3 & 538.4 & 21.0 & 77.8 & 526.2 & 22.4 \\
\hline Nanol & 79.6 & 514.3 & 20.6 & 79.7 & 514.7 & 20.3 \\
\hline Nano2 & 78.3 & 521.9 & 21.8 & 77.9 & 517.8 & 22.1 \\
\hline Nano3 & $\begin{array}{r}4.9 \\
72.1\end{array}$ & $\begin{array}{l}463.9 \\
518.2\end{array}$ & 20.7 & 77.9 & 520.4 & 21.9 \\
\hline Nano4 & 78.7 & 519.0 & 21.5 & 77.8 & 515.3 & 22.0 \\
\hline
\end{tabular}

Table 5. Water permeation data.

\begin{tabular}{|c|c|c|c|c|}
\hline \multirow{2}{*}{ Sample } & \multicolumn{2}{|c|}{ WVT (g.day ${ }^{-1} \cdot \mathrm{m}^{-2}$ ) } & \multicolumn{2}{|c|}{$P\left(E^{10}\right)\left(g \cdot P^{-1} \cdot s^{-1} \cdot m^{-1}\right)$} \\
\hline & Extrusion & Casting $^{[9]}$ & Extrusion & Casting $^{[9]}$ \\
\hline PC w/ Proc. & $28.0 \pm 1.0$ & $54 \pm 3$ & $9.4 \pm 0.6$ & $8.1 \pm 0.4$ \\
\hline Proc. PC & $18.0 \pm 2.0$ & - & $9.0 \pm 2.0$ & - \\
\hline $\mathrm{PC} / \mathrm{PCs}$ & $16.6 \pm 0.8$ & $194 \pm 5$ & $7.0 \pm 0.4$ & $14 \pm 5$ \\
\hline Nano1 & $15.2 \pm 0.7$ & $180 \pm 36$ & $7.7 \pm 0.3$ & $44 \pm 24$ \\
\hline Nano2 & $15.2 \pm 0.9$ & $49 \pm 23$ & $7.7 \pm 0.4$ & $12 \pm 5$ \\
\hline Nano3 & $17.0 \pm 1.0$ & $75 \pm 59$ & $8.0 \pm 1.0$ & $7.0 \pm 2$ \\
\hline Nano4 & $13.6 \pm 0.5$ & $200 \pm 84$ & $7.3 \pm 0.4$ & $24 \pm 2$ \\
\hline
\end{tabular}

this reduction is smaller. There are reports in the literature of the occurrence of degradation due to the addition of clay $^{[20]}$. The degradation temperature decreased with the increase of the clay content, and increased again for the sample with a higher content of modified clay (Nano 4). This behavior suggests a saturation limit for the influence of the presence of the clay ${ }^{[9]}$.

Flakes were the sample form before film extrusion, and its analysis is important to states if there is a difference in thermal properties after and before the last processing step. It was observed that the sample residue is kept practically constant for the both sample types. It is important to recall that is not characteristic of $\mathrm{PC}$ to degrade with complete conversion into volatiles products in the case of thermogravimetrics tests performed in inert atmosphere, having always a level of residual ashes. This fact explains the high residue content, which corresponds not only to the inorganic material present in the sample, but also the ash content inherent to the PC. The differences among temperatures of maximum mass loss between samples forms are due the geometric factor of the samples, where more compact samples, as films, have a heat transfer more efficient and present lower temperatures of maximum loss. This fact can be considered also as an indication that the last processing step does not significantly alter the sample, i.e., does not causes significant degradation.

\subsection{Dynamic-Mechanical Analysis (DMA)}

The most common use of DMA technique is the determination of $\mathrm{T}_{\mathrm{g}}$ and secondary transitions related with small chain portions or side groups of the polymeric chain. The technique, however, is generally underestimated. DMA results are sensible enough to be also useful to determine phase separation and interaction among components of a blend ${ }^{[21,22]}$ and therefore can be used in morphology discussions.

Figure 5a presents the loss modulus for samples of processed $\mathrm{PC}, \mathrm{PC}$ without processing and $\mathrm{PC} / \mathrm{PCs}$ blend. It can be noticed that the $\mathrm{T}_{\mathrm{g}}$ of both neat $\mathrm{PC}$ are close to $150^{\circ} \mathrm{C}$, as expected and corroborated by DSC tests. The neat samples present sub- $\mathrm{T}_{\mathrm{g}}$ transition around $80-90^{\circ} \mathrm{C}$. The $\mathrm{PC} / \mathrm{PCs}$ blend presented two peaks below $\mathrm{T}$, being the first around $30^{\circ} \mathrm{C}$, and the second around $80{ }^{\circ} \mathrm{C}$. These peaks are related to intersegment motion of PC chain and formation of PCs phase, respectively. These results indicated that the sulfonation changes significantly the polymer chains mobility, leading to a reduction of the $T_{g}$, as well as phase separation between sulfonated polycarbonate and non-modified polycarbonate ${ }^{[8,9]}$.

Figure 5b shows loss modulus for PC/PCs blend and the nanocomposites. It is noticed that the nanocomposites do not show a peak in $91{ }^{\circ} \mathrm{C}$, differently from $\mathrm{PC} / \mathrm{PCs}$ blend. A possible explanation is the clay addition shift the peak for higher temperatures values, where it overlaps to the $\mathrm{T}_{\mathrm{g}}$ peak of the PC. All nanocomposites presented a secondary transition around $25^{\circ} \mathrm{C}$, related with relaxation of chain segments of the PC non-modified main chain. Samples Nano3 and Nano4 showed peaks of higher intensity indicating higher interaction of the modified Clay with the non-sulfonated phase ${ }^{[8,9]}$.

\subsection{Water vapor uptake}

The transport of small molecules through a homogeneous membrane is usually described by a process where the permeant molecules adsorb at the surface, migrate to the opposite surface due to a concentration gradient and evaporate from the posterior surface to the environment. Therefore, the permeation of vapor through polymeric materials involves distinct processes of sorption, diffusion and desorption of the penetrant ${ }^{[23]}$. 
The transport properties of a gas, vapor or liquid in a polymer material are ruled by several factors, some of them depending of the properties of the penetrating species (in this case, the gas or vapor), the properties of the polymer and the interaction degree between them. The environment conditions are important as well. Among the influencing factors, stand out the chemical nature of the polymer and the permeant molecules, that influences in the diffusion and solubility parameters and consequently in permeation, and also the polymer phase morphology.

Table 5 presents the average values of water vapor transmission (WVT) and permeability (P). For comparing, data for casting films obtained in previous work ${ }^{[9]}$ are presented too.

The first difference to be discussed is the higher permeation of water for casting films than processed films. It is common knowledge that solvent evaporating process can generate more voids into membranes than the molten state processing. Firstly, the slow exit of solvent permits molecular mobility through longer times, what can lead to ordering of molecules, crystallization and phase separation. Secondly, the exit of solvent can lead defects to film core and surface, depending on drying velocity of the casting solution $^{[24,25]}$. All these factors can be responsible by higher permeation of the casting films.

The insertion of bulky groups in polymeric chain by sulfonation increases the free volume, what usually facilitates the transport of permeant through the membrane. The results obtained, however, show a reduction in WVT and $\mathrm{P}$ with the sulfonation. We believe that the increase in polarity is acting toward to retain the humidity into membrane phase ${ }^{[8,9]}$. This effect is observed in both processed and casting films.

The sepiolite addition is believed to have the same effect of sulfonation in nanocomposites which is to facilitate water transport through membranes by forming preferential channels. However, the data shows that the addition of clays reduces slightly the WVT values in all cases for processed films. A probable explanation for this behavior is that the sepiolite is well dispersed and distributed into polymeric matrix, increasing the tortuosity of the path the water vapor molecules need to take to pass through the film sample. These effects can be associated to the processing method, which do not permit molecular rearrangement and migration through phases, freezing a less ordered structure of the blend.

In general, the results are very different between processed and cast films, indicating that the material processing has a great role in blend morphology, resulting in very different transport properties, by reasons already discussed. Besides, the difference in small molecules transmission properties among nanocomposites are higher for samples prepared through casting process, indicating a reduced influence of the chemical nature of the clay surface into the blend morphology development, what is in agreement with the rapid establishment of film structure in processed films.

\section{Conclusions}

Membranes of nanocomposites blends of PC/PCs with sepiolite were produced with good optical properties, good mechanical resistance and with maintenance of the sulfone sites, as detected by FTIR and thermal analysis. Phase separation in the systems studied was confirmed by DMA.
The WVT tests showed that the melt state processing play an important role in the clay-matrix interaction as compared to samples prepared by casting procedure, decreasing water permeation and indicating that the transposition of casting process for the preparation of polymer membranes to a melt extrusion process needs more detailed and specific development.

\section{Acknowledgements}

The authors are grateful to the funding agencies Coordination for the Improvement of Higher Education Personnel (CAPES), National Council for Scientific and Technological Development (CNPq) and São Paulo Research Foundation (FAPESP) by financial support, and SABIC by donation of PC.

\section{References}

1. Larminie, J., \& Dicks, A. (2003). Fuel cell systems explained. Chichester: John Wiley. http://dx.doi.org/10.1002/9781118878330.

2. O'Hare, R. P., Cha, S. W., Colella, W., \& Prinz, F. B. (2006). Fuel cells fundamentals. New York: John Wiley.

3. Wu, J., Yuan, X. Z., Martin, J. J., Wang, H., Zhang, J., Shen, J., Wu, S., \& Merida, W. (2008). A review of PEM fuel cell durability: Degradation mechanisms and mitigation strategies. Journal of Power Sources, 184(1), 104-119. http://dx.doi. org/10.1016/j.jpowsour.2008.06.006.

4. Pinto, B. P., Santa Maria, L. C., \& Sena, M. E. (2007). Sulfonated poly(ether imide): A versatile route to prepare functionalized polymers by homogenous sulfonation. Materials Letters, 61(1112), 2540-2543. http://dx.doi.org/10.1016/j.matlet.2006.09.060.

5. Park, C. H., Lee, C. H., Guiver, M. D., \& Lee, Y. M. (2011). Sulfonated hydrocarbon membranes for medium-temperature and low-humidity proton exchange membrane fuel cells (PEMFCs). Progress in Polymer Science, 36(11), 1443-1498. http://dx.doi.org/10.1016/j.progpolymsci.2011.06.001.

6. Ehrenstein, G. W., \& Kabelka, J. F. (1992). Reinforced plastics. In F. Ullmann (Ed.), Ullmann's encyclopedia of industrial chemistry (Vol. 28, Cap. 8, pp. 603-612). Berlin: VCH Publishers.

7. Ruiz-Hitzky, E. (2001). Molecular access to intracrystalline tunnels of sepiolite. Journal of Materials Chemistry, 11(1), 86-91. http://dx.doi.org/10.1039/b003197f.

8. Gomes, A. C. O., Uieda, B., Tamashiro, A. A., Ruvolo Filho, A. C., Pessan, L. A., \& Paranhos, C. M. (2014). Membranas híbridas com potencial uso em células a combustível - parte 1: nanocompósitos de poli(eterimida) sulfonada. Polímeros: Ciência e Tecnologia, 24(4), 464-473. http://dx.doi.org/10.1590/01041428.1131 .

9. Gomes, A. C. O., Machado, I. M. M., Ruvolo, A. C., Fo., Pessan, L. A., \& Paranhos, C. M. (2014). Membranas híbridas com potencial uso em células a combustível - parte 2: nanocompósitos de poli(carbonato) sulfonado. Polimeros: Ciência e Tecnologia, 24(3), 402-410. http://dx.doi.org/10.4322/polimeros.2013.049.

10. Lakshmi, R. T. P. S., Bhattacharya, S., \& Varma, I. K. (2006). Effect of sulfonation on thermal properties of poly (ether imide). High Performance Polymers, 18(2), 115-126. http:// dx.doi.org/10.1177/0954008306056503.

11. Pinto, B. P., Santa Maria, L. C., \& Sena, M. E. (2007). Sulfonated poly(ether imide): a versatile route to prepare functionalized polymers by homogenous sulfonation. Materials Letters, 61(3), 2540-2543. http://dx.doi.org/10.1016/j.matlet.2006.09.060.

12. Sanchez, J.-Y., Chabert, F., Iojoiu, C., Salomon, J., El Kissi, N., Piffard, Y., Marechal, M., Galiano, H., \& Mercier, R. (2007). Extrusion: an environmentally friendly process for 
PEMFC membrane elaboration. Electrochimica Acta, 53(4), 1584-1595. http://dx.doi.org/10.1016/j.electacta.2007.04.022.

13. Alkan, M., Tekin, G., \& Namli, H. (2005). FTIR and zeta potential measurements of sepiolite treated with some organosilanes. Microporous and Mesoporous Materials, 84(1-3), 75-83. http:// dx.doi.org/10.1016/j.micromeso.2005.05.016.

14. Genies, C., Mercier, R., Sillion, B., Cornet, N., Gebel, G., \& Pineri, M. (2001). Soluble sulfonated naphthalenic polyimides as materials for proton exchange membranes. Polymer, 42(2), 359-373. http://dx.doi.org/10.1016/S0032-3861(00)00384-0.

15. Smitha, B., Sridhar, S., \& Khan, A. A. (2003). Synthesis and characterization of proton conducting polymer membranes for fuel cells. Journal of Membrane Science, 225(1-2), 63-76. http://dx.doi.org/10.1016/S0376-7388(03)00343-0.

16. Abts, G., Eckel, T., \& Wehrmann, R. (1992). Polycarbonates. In F. Ullmann (Ed.), Ullmann's encyclopedia of industrial chemistry (Vol. 21, Cap. 2, pp. 207-214). Berlin: VCH Publishers.

17. Hevesut, H., Otsuka, H., \& Imai, N. (1969). Infrared study of sepiolite and palygorskite on heating. The American Mineralogist, 53(nov-dec), 1613-1624.

18. Turhan, Y., Turan, P., Doĝan, M., Alkan, M., Namli, H., \& Demirbas, O. (2008). Characterization and adsorption properties of chemically modified sepiolite. Industrial \& Engineering Chemistry Research, 47(6), 1883-1895. http:// dx.doi.org/10.1021/ie070506r.

19. Hande, V. R., Rath, S. K., Rao, S., \& Patri, M. (2011). Crosslinked sulfonated poly (ether ether ketone) (SPEEK)/reactive organoclay nanocomposite proton exchange membranes (PEM).
Journal of Membrane Science, 372(1-2), 40-48. http://dx.doi. org/10.1016/j.memsci.2011.01.042.

20. de la Orden, M. U., Pascual, D., Antelo, A., Arranz-Andrés, J., Lorenzo, V., \& Martínez Urreaga, J. (2013). Polymer degradation during the melt processing of clay reinforced polycarbonate nanocomposites. Polymer Degradation \& Stability, 98(5), 11101117. http://dx.doi.org/10.1016/j.polymdegradstab.2013.03.024.

21. Lucas, E. F., Soares, B. G., \& Monteiro, E. E. C. (2001). Caracterização de polímeros - determinação de peso molecular e análise térmica. Rio de Janeiro: e-Papers.

22. Sepe, M. P. (1998). Dynamic mechanical analysis for plastics engineering. New York: Plastics Design Library.

23. Chinellato, A. C., Vidotti, S. E., Moraes, M. B., \& Pessan, L. A. (2007). Effects of plasma etching on surface modification and gas permeability of bisphenol-a polycarbonate films. Journal of Macromolecular Science, Part B: Physics, 46(6), 1165-1177. http://dx.doi.org/10.1080/00222340701582928.

24. Qipeng, G., editor (2016). Polymer morpohology. principles, characterization, and processing. New Jersey: John Wiley \& Sons Inc.

25. Baker, R. W. (1991). Membrane separation systems: recent developments and future directions. Michigan: Noyes Data Corporation. 